REVISTA ARA N8. VOLUME 8 . OUTONO+INVERNO 2020 • GRUPO MUSEU/PATRIMÔNIO FAU-USP

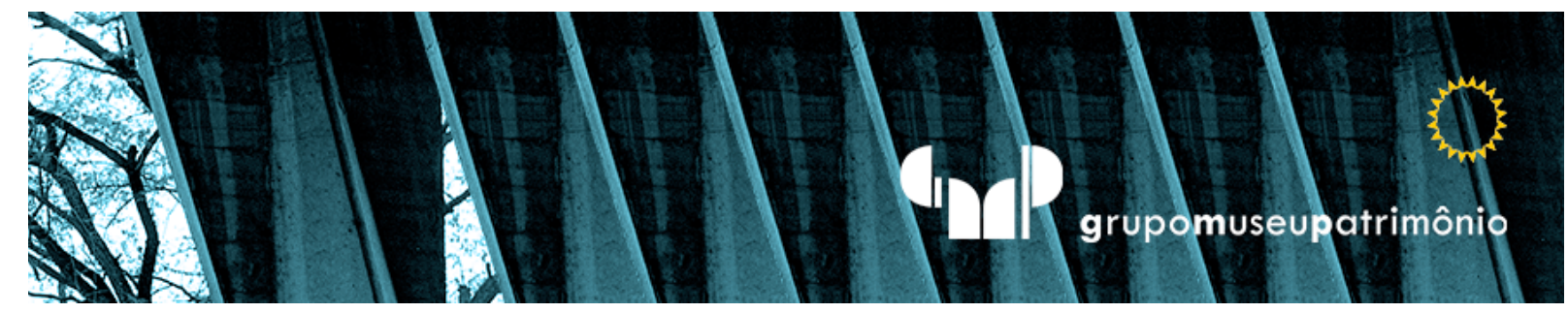

\title{
Imagens: passagens e projeções
}

Imágenes: pasajes y proyecciones

Images: passages and projections

\author{
Carmen S. G. Aranha
}

Museu de Arte Contemporânea da Universidade de São PauloMAC USP

São Paulo/BR - e-mail: saranha@usp.br 


\title{
Resumo
}

Apresentam-se aqui diálogos revelados em Memorial do desenho, pesquisa curatorial realizada no MAC USP. Discute-se o desenho como elemento fundamental na construção da compreensão da imagem contemporânea. A partir da fenomenologia do olhar de Merleau-Ponty, destacam-se aspectos motivadores para a compreensão de relações estéticas das proposições curatorial e museográfica da mostra.

Palavras-Chave: Desenho Moderno. Desenho Contemporâneo. Memória. Fenomenologia. Percepção.

\section{Resumen}

Aquí se presentan diálogos revelados en Memorial do Desenho, investigación curatorial realizada en MAC USP. El dibujo se discute como un elemento fundamental en la construcción de la imagen contemporánea. Desde la fenomenología de la mirada de Merleau-Ponty, se destacan aspectos motivadores para la comprensión de las relaciones estéticas de las propuestas curatoriales y museográficas de la exposición.

Palabras-Clave: Diseño moderno. Dibujo Contemporáneo. Memoria. Fenolomenología. Percepción.

\begin{abstract}
Here are presented dialogues revealed in Memorial do Desenho, curatorial research carried out at MAC USP. Drawing is discussed as a fundamental element in the construction of the contemporary image. From the phenomenology of the Merleau-Ponty gaze, motivating aspects are highlighted for the understanding of aesthetic relations of the curatorial and museographic propositions of the exhibition
\end{abstract}

Keywords: Modern Drawing. Contemporary Drawing. Memory. Phenolomenology. Perception. 


\section{INTRODUÇÃO}

(...) a obra não é espetáculo de alguma coisa, a não ser espetáculo de um
nada, de uma invisibilidade. Arrebenta a pele das coisas para mostrar como as coisas se fazem. (MERLEAU-PONTY, 2004, p. 37).

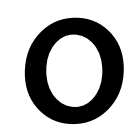

museu de arte se inscreve no imaginário coletivo como um lugar de conhecimento, lazer e de possibilidades de práticas educativas. $\mathrm{Na}$ apreensão sensível da imagem da obra de arte, o museu se oferece ainda como um lugar no qual o tempo presente se estende às memórias, percepções, ao imaginário, projetando-os em modos de como a história das visualidades sedimenta a cultura. Mas hoje existe um tipo de consumo da imagem artística - nosso objeto de estudo - que tende a diluir a percepção de qualquer que seja essa apresentação. Esse enfraquecimento inicia-se pela perda de um olhar que poderia se envolver nos processos criadores junto com a imagem diante de nós. Distancia-nos assim da imagem que provoca uma interrogação ou daquela que, apesar de estar no meio de tantas outras, resiste ao sustentar uma intenção desenhada em sua estrutura, a reflexão invisível de uma visão vivida pelo artista e tornada visível. Nesse ponto, indaga-se: quais sentidos o museu de arte oferece ao pretender se constituir como um lugar de 
construção de conhecimento da imagem-enigma? Essa é a questão fundamental que inicia e move o presente ensaio.

\begin{abstract}
A imagem-enigma é que nos desorganiza; a realidade de uma ausência; uma inquietante estranheza; uma imagem com inacessibilidade; uma imagem adiada; um tumulto silencioso que impregna o imaginário do observador. (FABBRINI, 2019, p. 138).
\end{abstract}

Merleau-Ponty (1999, p. 408, 557, 564, 566, 605; 2004, p. 18), em suas reflexões sobre a fenomenologia da percepção e a fenomenologia do olhar, situa alguns conceitos motivadores que nos servem de apoio no entendimento de uma aproximação de processos criadores percebidos na imagem artística. "Percepção" e "campo de presença" são conceitos dessa filosofia, discutidos adiante, que oferecem uma compreensão e interpretação das movimentações dos atos de conhecimento de mundo que vão ao encontro dos processos da criação artística.

No sentido de refletir e descrever certas movimentações apreendidas em imagens significativas, por exemplo, na obra de arte, a exposição Memorial do desenho indicará algumas passagens da memória estética moderna à contemporânea por meio do desenho, considerando-as,- as passagens,- como o fenômeno que pode ser apreendido em sua visualidade de "imagemenigma". O desenho é visto aqui como uma linguagem de origem, estrutural, carregado de historicidade e apto a atravessar diversas temporalidades.

Essas premissas situam relações estéticas somadas à filosofia fenomenológica e estendidas à curadoria. Para tanto, num dado momento do trabalho, tomaremos como obras referenciais, nessa análise, Nu deitado, c. 1925, de Anita Malfatti (1889-1964), Minha mãe morrendo (no 9), 1947, Série Trágica, de Flavio de Carvalho, Costureiras, 1950, de Tarsila do Amaral (1886-1973), Célula mestra vampirizando células menores, 2001, de Rosana Paulino (1967) e Projeto Tarsila, Retrato (Raisonnè), 2011, de Gustavo von Ha (1977). As cinco

\footnotetext{
${ }^{1}$ (...) Uma extensão do mundo compartilhada pelo indivíduo, uma maneira ativa de ser num fluxo de temporalidade, um entendimento amplo do presente atual enquanto presente efetivo, o qual envolve um passado imediato e um futuro próximo. (FONSECA, 2012, p. 81).
} 
obras são consideradas imagens que carregam aspectos de uma memória estética e, ao mesmo tempo, juntas constituem uma passagem do desenho moderno ao contemporâneo.

\title{
A IMAGEM DE $1^{\text {a }}$ GERAÇÃO
}

O termo "imagens de primeira geração" é usado por Joseph Beuys (1921-1986) para designar a linguagem artística "desenho". Segundo esse artista, na origem do ato de desenhar, há um a priori visual de mundo no pensamento que, ao se tornar expressão, realiza uma "dobra", um movimento de transformação de um ponto de forças invisíveis em coisas visíveis (BEUYS, apud ADRIANI, p. 1012). Beuys está se referindo então ao momento da gênese da criação artística, na qual há uma imagem a ser construída visualmente. Nessa concepção sobre o desenho, torna-se relevante entender o ato de transformação do pensamento em expressão. Merleau-Ponty (2004, p. 18-19) diz que a palavra imagem foi pensada como um desenho de mundo numa réplica exata.

\begin{abstract}
A palavra imagem é mal afamada porque se julgou irrefletidamente que um desenho fosse um decalque, uma cópia, uma segunda coisa, e a imagem mental um desenho desse gênero em nosso bricabraque privado. Mas se de fato ela não é nada disso, o desenho e o quadro não pertencem mais que ela ao em si. Elas são o dentro do fora e o fora do dentro, que a duplicidade do sentir torna possível e sem os quais jamais se compreenderá a quasepresença e a visibilidade iminente que constituem todo o problema do imaginário. (MERLEAU-PONTY, 2004, p. 19).
\end{abstract}

A imagem vista como uma "quase-presença" ou uma "visibilidade iminente" tem uma estrutura de pensamento a ser nela reconhecida. A apreensão da imagem artística significativa requer um trabalho. Segundo Didi-Huberman (2013, p. 23), "ao fruidor, exige uma inquietação que atua constantemente nos entrelaçamentos ou mesmo no imbrólio de saberes transmitidos e deslocados, de não-saberes produzidos e transformados (...)".

Hoje, se levarmos em consideração a relação, cada vez mais próxima, dos indivíduos com as imagens veiculadas, observaremos que os fruidores têm um 
olhar de sobrevôo, um olhar flutuante que não realiza trocas entre mundo vivido e a cultura própria. Se existe, como diz Merleau-Ponty (1980, p. 90), "um exterior do interior e um interior do exterior que a duplicidade do sentir torna o reconhecimento possível", nossa visão se faz no mundo com uma visibilidade secreta. Essa apreensão demanda um tempo para se construir. As tensões recolhidas no mundo da vida podem alojar-se no ser sem nenhum discurso, apenas como sensações, mas nossas inquietações já são sinais que, como diz Paul Klee (2011), temos pré-histórias do visível, cifras desenhadas num imaginário, inquietações vividas.

Na contemporaneidade, as inúmeras imagens correm diante de nós, não se completam na percepção, nesse forro de invisibilidades (MERLEAU-PONTY, 2004 , p. 18). As trocas do indivíduo com o mundo intercambiam-se constantemente. A algaravia de um sem número de relações faz emergir uma síntese geral da cultura de imagens, porém, deslocada do "olhar", uma impressão geral de uma cultura de simulacros, um argumento efetivo para a ideia difundida de que vivemos numa sociedade de imagens.

Os simulacros são imagens hegemônicas na sociedade da hipervisibilidade, como as que circulam na "tela total": computador, video, televisão ou celular. São "imagens obscenas", segundo Baudrillard, no sentido de que nada escondem, ou dão tudo a ver, e não "imagens sedutoras", porque nessas algo ainda restaria fora da cena, ou mesmo em oposição à cena (...). (FABBRINI, 2019, p. 131).

Com as imagens-simulacros, a percepção se transforma. As imagens nos chegam rapidamente; são apreendidas em sucessões vertiginosas e como diz Sarlo (2004, p. 53), "a compreensão não está aparelhada para essa veloz e dupla decodificação simultânea de áudio e vídeo". Ainda segundo a autora, nossa sociedade veicula imagens, mas imagens sem intensidade, sem intenções. Assim, vivemos uma suspensão do tempo, tantos signos nos prendem apenas ao presente e o sentido da imagem passa despercebido nesse cenário. Não percebê-la é dar lugar às imagens de segunda geração que, sem a estrutura da primeira visualidade do pensamento, perdem origem, estrutura e 
historicidade nas inúmeras vezes que são redesenhadas; nossa percepção se enfraquece nesse contexto de proposições vagas, e incessantes "agoras".

A "imagem-enigma" recupera a potência da percepção do fenômeno da vida ali expressado. Como falar da percepção como ato de conhecimento de mundo diante dessa imagem? Com a percepção, podemos nos envolver na construção de ver o mundo e pensar sobre o que se está vendo. "É um ato que não se coloca aparte do fim ao qual está dirigido" (MERLEAU-PONTY, 1978, p. 374). Percepção e percebido, necessariamente, trocam a presença de alguma coisa do objeto de mundo no em si.

De fato, a percepção refere-se ao exercício do pensamento que não se realiza como posse do objeto ali adiante ou de um recorte de impressões que se possa ter dele. Esse modo de cogitar sobre o mundo é um ato de compreensão-interpretação dos seus significados, estruturas ou de arranjos espontâneos de suas partes. A percepção origina-se num campo da experiência vivida no mundo com os objetos de uso criados pelo homem.

Podemos dizer que perceber é um ato de conhecimento que, ao mesmo tempo, se dirige ao contato com aquilo que é percebido, mas é também razão e construção do imaginário. Nos reconhecemos nas coisas do mundo.

$\mathrm{Na}$ raiz de todas as nossas experiências e reflexões encontramos, então, um ser que imediatamente se reconhece, porque é o conhecimento de si mesmo e de todas as coisas que possibilitam conhecer sua própria existência, não pela observação de um fato dado, nem pela interferência de alguma ideia de si mesmo, mas pelo contato direto com o mundo. (MERLEAU-PONTY, 1978, p. 371)

\section{IMAGEM, PERCEPÇÃO E LINGUAGEM TÁCITA}

Atualmente, muitos estudiosos nos colocam imersos na "cultura de imagens" e por isso mesmo, sua profusão não nos dá suficientes indícios para sabermos seus verdadeiros sentidos. Vivemos no mundo das imagens! Verdades da 
contemporaneidade que provocam distorções no conhecimento, inclusive na produção dos objetos chamados culturais, sem que interroguemos escolha e assimilação. Jameson (2006, p. 43-44) aponta "a perda da sociedade atual na capacidade de reter o seu próprio passado, e a viver em um presente perpétuo e em uma mudança perpétua que obliteram as tradições do tipo preservado, de um modo ou de outro, por toda informação social anterior". Com a percepção regida por uma temporalidade sem lastro, as imagens traduzem o conhecimento contemporâneo de mundo: com elas, diversas relações emergem e submergem e se lançam em argumentos que neutralizam qualquer possibilidade de compreensão de uma "imagem-enigma".

A obra de arte é um recorte, uma visão de mundo inscrita numa matéria, um lugar da cultura do artista expressado em imagem. Dar voz à imagem artística significa que "na compreensão de qualquer linguagem, o que conta é sua função conquistadora, que é do homem no esforço para dizer-se e dizer o mundo, a capacidade desbravadora da expressão" (CÂMARA, 2005, p. 181). Como acessar esses significados inscritos nos códigos da matéria? Diante da imagem, uma subjetividade silenciosa interroga "o sentido de se fazer afirmativas sobre a existência daquilo que nada se sabe ou conhecer um sinal que não se constitui como tal" (MERLEAU-PONTY, 1999, p. 370). Essa subjetividade silenciosa é ordenada por um cógito tácito com condição de linguagem (CARMAN e HANSEN, 2005, p. 151), ou melhor, é uma apreensão articulada da qualidade do que está diante de nós realizada com o corpo no trabalho. (CÂMARA, 2005, p. 129).

A apreensão da imagem, como "quase presença" ou "visibilidade iminente", demanda "apreensão de uma extensão do mundo compartilhada pelo indivíduo, uma maneira ativa de ser num fluxo de temporalidade, um entendimento amplo do presente atual enquanto presente efetivo, o qual envolve um passado imediato e um futuro próximo" (FONSECA, 2012, p. 81).

(...) O fluxo absoluto se perfila sob seu próprio olhar como 'uma consciência' ou como sujeito encarnado porque ele é um campo de presença - presença em si, presença a outrem e ao mundo - e porque esta presença o lança no mundo 
natural e cultural a partir do qual ele se compreende. Não devemos representá-lo como contato absoluto consigo, como uma densidade absoluta sem nenhuma fenda interna, mas ao contrário como um ser que se prossegue no exterior. (MERLEAU-PONTY, 1999, p. 605).

Maurice Merleau-Ponty (1999) ressalta que o tempo é dimensão originária do ser. Assim, a frase "uma maneira ativa de ser num fluxo de temporalidade" pode ser entendida pensando-se o tempo como presença percebida na experiência de mundo. Ou seja, em certos momentos, somos lançados numa fronteira entre natureza e cultura, "num entendimento amplo do presente atual enquanto presente efetivo, o qual envolve um passado imediato e um futuro próximo" (MERLEAU-PONTY, 1999, p. 557). O filósofo descreve, desse modo, o lugar da percepção como "profundidade deflagrada".

(...) Ela não pode ser o intervalo sem mistério que eu veria de um avião entre as árvores próximas e as distantes. Nem tampouco o escamoteação das coisas umas pelas outras que um desenho em perspectiva me representa vivamente: essas duas vistas são muito explícitas e não suscitam questão alguma. O que constitui enigma é a ligação delas, é o que está entre elas (...). (MERLEAUPONTY, 2004, p. 35).

Então, precisamos pensar que, entre as coisas do mundo, há ligações.

Há uma localidade global onde tudo está ao mesmo tempo, cuja altura, largura e distância são abstratas, de uma voluminosidade que exprimimos numa palavra ao dizer que uma coisa está aí. (MERLEAU-PONTY, 2004, p. 35).

O processo de formação da percepção da "imagem-enigma" é situado como a vivência de ligações entre as coisas visíveis da qual vamos nos aproximando. Cifras de sentidos evocam uma "pré-história do visível". Merleau-Ponty define esse ato como a construção de um panorama cultural próprio da experiência no mundo da vida, contra o qual destacamos nossos atos e atitudes. O que vejo reflete-se em mim, naquilo que o pensador $(2004$, p. 18) chama de "visibilidade secreta".

Qualidade, luz, cor, profundidade, que estão aí diante de nós, aí só estão aí porque despertam um eco em nosso corpo, porque este lhes faz acolhida. (Idem)

Esse ato de percepção abre uma via de acesso à experiência de nós mesmos, que é a presença da nossa cultura em si e a possibilidade de reconhecê-la 
como uma condição de construção de linguagem (CÂMARA, 2005, p. 129). Aproximarmo-nos desse fenômeno é realizar uma apreensão articulada e silenciosa de uma vivência significativa. É a presença dos indícios perceptivos, tanto da "imagem-enigma" quanto daqueles que podemos ter na experiência vivida. Criando ou vendo, podemos participar de processos originários da apreensão da qualidade do mundo.

A percepção é um ato de pensamento que se dirige às qualidades do mundo, às invisibilidades que dependem do olhar disponível para ver o que quer ver e no seu silêncio de olhar em direção ao mundo, vê um impensado.

\section{MEMORIAL DO DESENHO²: PASSAGENS E PROJEÇÕES}

A curadoria deve estabelecer o Jogo entre obras e o espaço que as circunda, além de correlacioná-los com as proposições do recorte curatorial. Esta é a função da curadoria em um museu de arte.

No sentido de nos aproximarmos do lugar da curadoria e museografia na compreensão das imagens buscamos, primeiro, um panorama que pudesse nos auxiliar com questões similares. Existe um paralelo entre a encenação de teatro, a curadoria e a museografia em artes visuais, já abordado em Aranha e Nicolau (2009): seguindo o cenógrafo Gianni Ratto (2001, p. 32), o texto, a direção e o ator devem ter uma interação a ponto de constituirem uma proposição só, onde tudo está ao mesmo tempo, (como uma profundidade deflagrada) sem ênfase em nenhuma das partes. Diz o autor,

Não esqueça: o teatro é Jogo (Jogo, não um jogo). Jogo é alegria, técnica e criatividade. Alegria pelo prazer que se deve provar ao fazê-lo; técnica para poder dominar todos os aspectos que determinam sua realização; criatividade, pois sem ela ficaremos limitados a virtuosíssimos estéreis. (RATTO, 2001, p. 32).

\footnotetext{
${ }^{2}$ Memorial do desenho está sendo exibida no Museu de Arte Contemporânea da Universidade de São Paulo (Avenida Pedro Álvares Cabral, 1.301, Ibirapuera, em São Paulo) até 28 de junho de 2020.
} 
Inspirados pelas palavras de Ratto sobre cenografia, resolvemos dar visualidade às "passagens e projeções" do desenho moderno ao contemporâneo, fazendo um paralelo já apropriado em curadoria anterior ${ }^{3}$. Analogamente, indagamos, como texto, diretor e ator se tornam "Jogo", como seria em nosso caso, a montagem de uma mostra de desenho? Como se dá a interseção desses elementos e como isso se torna "Jogo", ou melhor, como isso se torna "alegria", "técnica" e "criatividade", lembrando que essa movimentação busca também nossa proposta inicial sobre a pensatividade da imagem. Do texto curatorial, seu recorte pede uma encenação.

[...] Se vocês querem que eu sintetize numa frase a definição do que é a encenação eu direi: a encenação é a criação de um mundo (mundo de cores, de gestos, de luzes, de ritmos, mundo espiritual e mundo plástico) potencial no texto, no qual é necessário fazer penetrar o espectador de forma imperceptível e para o que é necessário facilitar-lhe o acesso. (RATTO, 2001, p. 65).

No caso da mostra Memorial do desenho, a interação dos curadores ${ }^{4}$ com a museógrafa ${ }^{5}$ possibilitou uma discussão profícua e a compreensão do estilo da exposição e dos imbricamentos do texto, do recorte, a proposta de construção espacial e a distribuição das "obras-atores".

O caminho pela exposição inicia-se na Mala, 1986-1987, de José Carratu (1955). A obra reflete certa dualidade, no caso da mostra Memorial do desenho. Indica a temática que se anuncia com os desenho sobre a superfície da valise e ao mesmo tempo, simboliza que pode haver um conteúdo a se levar.

Adentra-se o espaço claro do off white contrastante com o grafite ao fundo das paredes do edifício de Niemeyer (1907-2012) (Figura 1). Não quisemos interromper o espaço, e desse modo, criamos três subespaços no sentido da

\footnotetext{
${ }^{3}$ A exposição Samson Flexor. A dobra do desenho esteve em cartaz no Museu de Arte Contemporânea da Universidade de São Paulo, entre 25 de janeiro de 2015 a 28 de abril de 2019.

${ }^{4}$ A curadoria da mostra contou com a assistência de pesquisa do educador Evandro Carlos Nicolau do Setor Educativo do MAC USP.

${ }^{5}$ Elaine Maziero fez a museografia da exposição.
} 
profundidade da sala de exposições. Niemeyer sempre evoca uma espacialidade clara e limpa. Seguimos essa percepção arquitetônica.
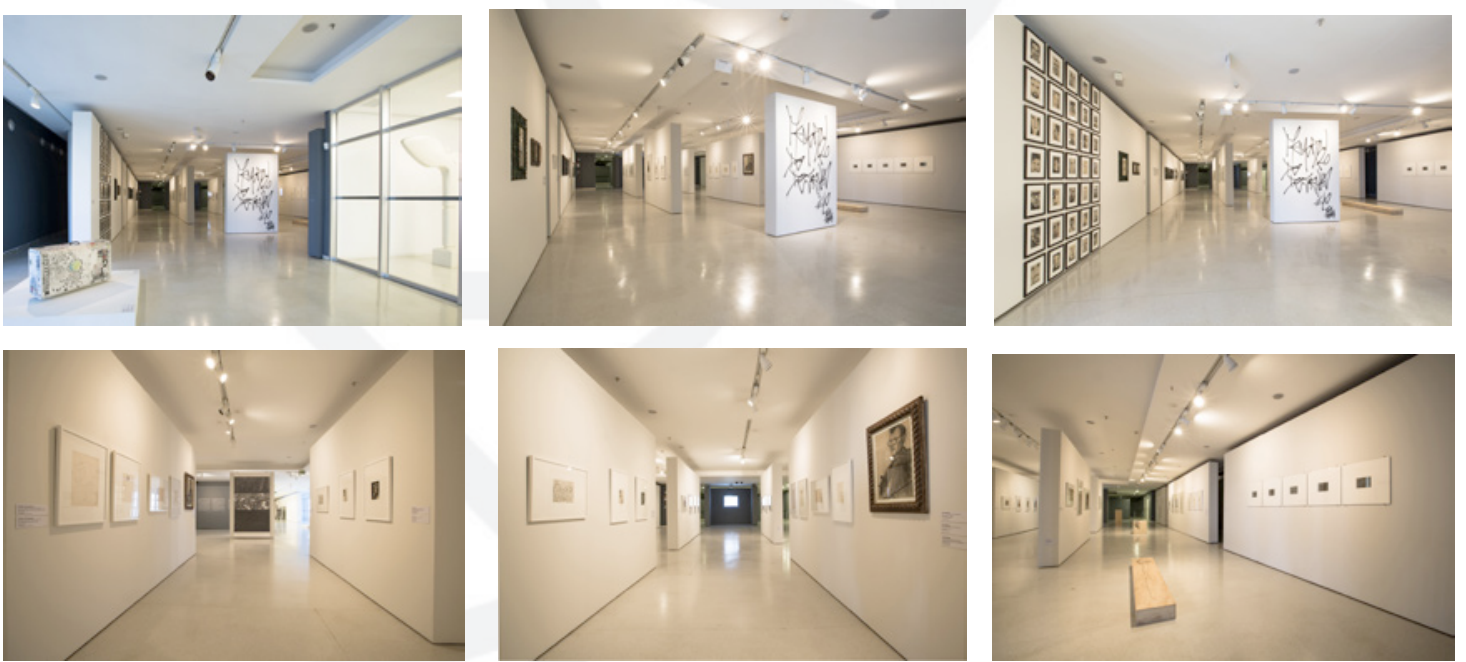

Figuras 1 a 6. Memorial do desenho. Fotografias: Elaine Maziero

Ao fundo do espaço mediano, um video projeta $O$ Gato acorrentado a um só traçado, 1977, de Gabriel Borba (1942) (Figura 4) e num movimento oposto, o desenho a grafite de Donald Urquhart (1963), A Drawing Conceived in São Paulo, 07/11/2018 (Figura 5). No verso desse painel, o título da exposição se proclama sem conseguir ser decifrado. A princípio ilegível, mas aos poucos reconhecido na grafia tantas vezes usada na cidade, é um grafite como nome da exposição, Memorial do desenho, 2019, de Rodrigo Amor Experimental. (Figuras 2 e 3)

Olhamos à esquerda e nos deparamos com Book of faces of facebook de Zed Nesti, de 2009/2010, Gustavo von Ha e seu Projeto Tarsila (Figura 5). Mas seguir em frente, após o grafite de Rodrigo Amor Experimental, significa adentrar o núcleo mais clássico da exposição. É lá que queremos estar. Com Ismael Nery, Tarsila do Amaral, Anita Malfatti, Di Cavalcanti, Pennacchi, Raphael Galvez, Pancetti e Portinari (Figuras 4 e 5). 
Poderíamos ter seguido os painéis da esquerda e olharíamos para os desenhos de Edith Derdick, Mira Schendel, Léon Ferrari, Amílcar de Castro, Leonilson e Gerda Brentani com Fábrica Francisco Matarazzo 1900, de 1984 (Figura 2). Ou seguimos à direita e refletiríamos sobre Honoré Marius Bèrard. A obra mais antiga da mostra (1913) tem à sua frente Christiana Moraes, Rosana Paulino e John Parker, com desenhos de 2003, 2001 e 2017/2018. Em painéis contíguos a Bèrard, John Graz, Marcelo Grassmann, Flávio de Carvalho e Victor Brecheret. Donald Urquhart, além de A Drawing Conceived in São Paulo, 07/11/2018, Line Sky 1-5, de 2017. Estendidos no chão da exposição, três desenhos de Vitor Mizael (1982) em grafite sobre caixas de madeira, de 2014/2015 (Figura 6).

A partir dos percursos que se pode fazer, a partir, também, de um cenário geral, começamos a nos deter no "Jogo". Cada uma das linhas que compõem os desenhos constrói com esse elemento estrutural as falas dos atores. Agora eles estão no cenário. $O$ texto procura entrelaçar os desenhos da exposição Memorial do desenho que atuam ora deixando vestígios da arte moderna, ora dando indícios de uma contemporaneidade.

lluminados por materiais e técnicas, o grafismo moderno engendra espaços, planos, profundidades, tramas, massas, luzes, movimentos, direções e intensidades e todas as ligações entre as aparições da linha acabam por designar o desenho.

Mas não podemos esquecer que a função de ensaio é uma característica dessa linguagem artística, mesmo após o moderno. Desenhar é registrar, é anotar graficamente formas da observação, da memória, da razão, da emoção, da intuição e das próprias sensações (NICOLAU, 2005). Entretanto, desenhar é, também, um ato de criação e relembrando Beuys, é um ato que transforma forças invisíveis e um pensamento de ver apreendido no mundo da vida, em imagem visual.

Mas, a função da linguagem modificou-se com o surgimento de materiais e técnicas da modernidade e modernidade tardia. Aí as linguagens se distanciam 
de conceitos-motivadores acadêmicos e do desenho, ao lado de todas as artes visuais, emancipa-se para criar outros desígnios. Diante disso, começa uma inversão de afirmativas, ou mesmo de modelo, ou seja, a linha no desenho abandona a função de ser apenas esboço para se tornar "obra-projeto" por um lado e "obra em si mesma" por outro. E o mais interessante é que agora constrói um diálogo, em sua função fundante, com outras linguagens.

Os atores estão dando "alguns alertas": mesmo sendo a linha a principal condição de existência do desenho, o olhar deve apreendê-la como abstração, pois somente tem presença entre as coisas do mundo, como se fosse uma tensão disposta nos espaços. A linha tem uma condição de ausência, por não ser o invólucro das coisas e uma condição de presença, por situar o surgimento do invisível. E como reconhecer as passagens de memórias estéticas? Elas seriam os desenhos em si? Sim, os desenhos evidenciam suas historicidades na linha, na temática, nos materiais, nos procedimentos e nos seus interstícios, nas ligações que fazem situam as transformações da arte moderna para a contemporânea. Os olhares se cruzam, não há um olhar utópico. E agora, como ver?

\section{MEMÓRIA ESTÉTICA: DESENHO E VISUALIDADE}

Cinco desenhos da exposição Memorial do desenho oferecem algumas passagens da memória estética moderna à contemporânea, fenômeno esse apreendido como uma visualidade que exercita um olhar criador na apreensão da "imagemenigma", fundamentado por certos aspectos da fenomenologia do olhar.

A exposição Memorial do desenho apresenta-se como lugar de anamnese, onde o desenho preserva traços de visualidades do século $X X$ e, sincronicamente, os impele ao século XXI. Um dos caminhos possíveis para fruição é observar a trajetória que subverte o tempo nas obras instaladas. Nas relações Inter-obras, coexistem formas que se mostram sequenciais, múltiplas e complexas. Por intermédio das imagens ali presentes o espectador pode desvelar pretérito, presente e prospectivas da arte. 
Ao olharmos esses desenhos compreendemos a "quase-presença" de MerleauPonty (2019, p. 138). Nessas obras, vemos que ali se encontravam as imagens que nos desorganizam, indicam uma ausência presente, uma inquietante estranheza, como Fabbrini aponta quando fala sobre a "imagem-enigma".

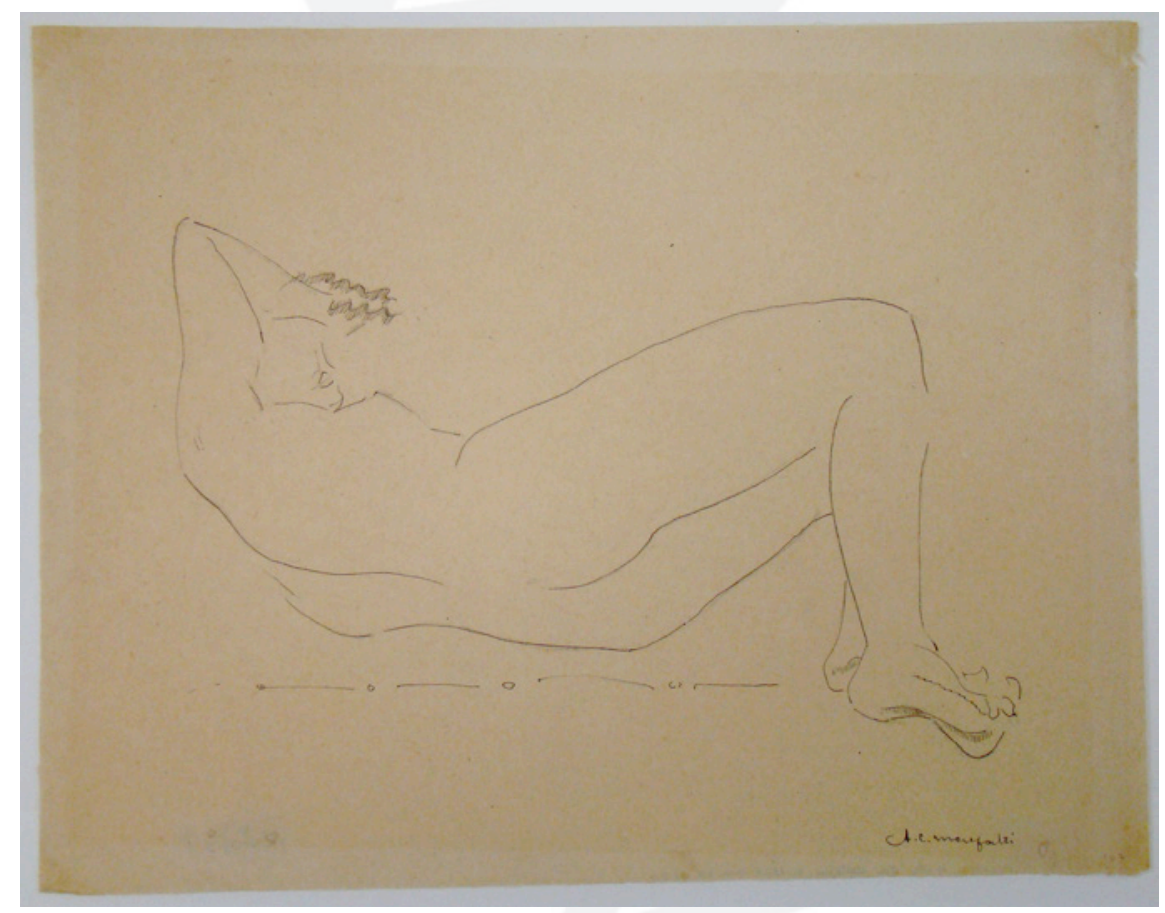

Figura 7. Anita Malfatti, Nu deitado, c. 1925. Acervo MAC USP.

O desenho de Anita Malfatti, Nu deitado, c. 1925 (Figura 7), é um exercício do nu (o estudo da figura humana, consagrado desde o clássico). No início do século $\mathrm{XX}$, os artistas modernos eram exímios desenhistas da observação do modelo da natureza, ou no caso, do modelo vivo. O desenho de Anita demonstra esse domínio. Suas linhas movimentam-se no limite das materialidades: essa tensão entre corpo e espaço dá origem a uma linha orgânica suave que envolve o modelo com intensidades diversas, dada pela espessura do gesto que marca o contorno da figura e pela luz do grafite, às vezes, mais tênue e outras, mais precisa. A figura feminina, em diagonal, 
penetra no espaço e recua para o plano do fundo. Nesse desenho esmaecido, com traços leves, mas precisos - talvez um primeiro esboço que Malfatti cria no exercício do desenhar: um corpo contorcido, a flexão dos joelhos, os pés indicados, os braços sobre a cabeça e uma profundidade inteira deflagrada.

Figura 8: Flávio de Carvalho, Minha mãe morrendo, 1947, Acervo MAC USP.

Flavio de Carvalho, com Minha mãe morrendo, no. 9, último desenho da Série Trágica, de 1947. Flavio formou-se me engenharia civil e atuou como arquiteto, cenógrafo, figurinista, teatrólogo, poeta, artista plástico. Nessa Série, o artista cria um exercício de apropriação da essência expressiva da agonia de sua mãe. A linha aqui se torna movimento puro. Todas as suas movimentações indicam uma essencialidade: a aproximação da morte. As densidades construídas por traços suaves, às vezes, adensados; as gestuações são concisas ou mais extensas. Linhas enfatizam certos contornos da cabeça 
apoiada, desenham o olhar semicerrado e a boca entreaberta. Outras, sem grandes luminosidades, destacam-se da figura para se esvaírem no espaço ao redor da mãe e criar um espaço multidimensional, uma profundidade dentro de outra profundidade, a qual está por vir. Todas as movimentações foram compostas por inúmeras correlações formais da linguagem entrelaçadas com as movimentações das técnicas e dos materiais, surgindo daí o desenho de Flavio de Carvalho.

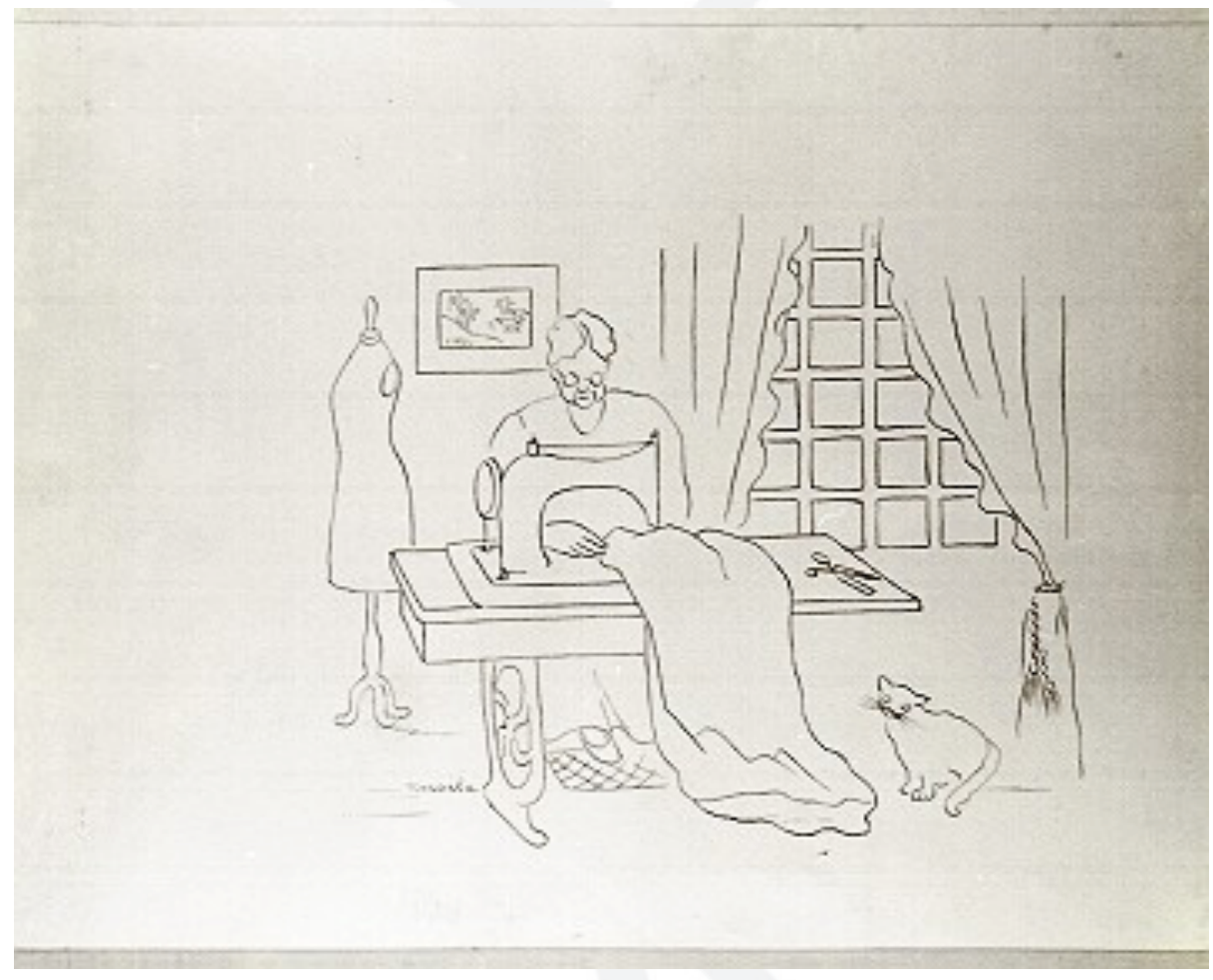

Figura 9. Tarsila do Amaral, Costureiras, sd. Acervo MAC USP.

Tarsila do Amaral, aproximadamente 25 anos depois do exercício de Malfatti, nos mostra a figura da mulher no mundo do trabalho. 0 desenho Costureiras, sd (Figura 9) pode ser considerado desdobramento temático da pintura Costureiras, de 1950 (também pertencente ao acervo do MAC USP). Cada um dos objetos do desenho é expresso numa observação precisa da artista: a janela, emoldurada pela cortina de poucos traços e o quadro compõem o plano de fundo; o manequim atrás da costureira aponta o penúltimo plano. As linhas da 
temática principal, a costureira, penetram-se pelos objetos: máquina de costura, pedal, tecido estendido sobre a mesa, e dialogam com a clareza de quem compreende os desígnios dessa linguagem. A profundidade clássica apropriada e se desenrola em planos precisos, do primeiro ao último. Tarsila desenha a nanquim com bico de pena, material usado, assim como o grafite e o carvão, para os exercícios de desenho. Essa observação realista remonta às temáticas ideológicas levantadas por Operários e Segunda Classe (ambos de 1933), numa tendência ao realismo social após sua viagem à, então, União Soviética.

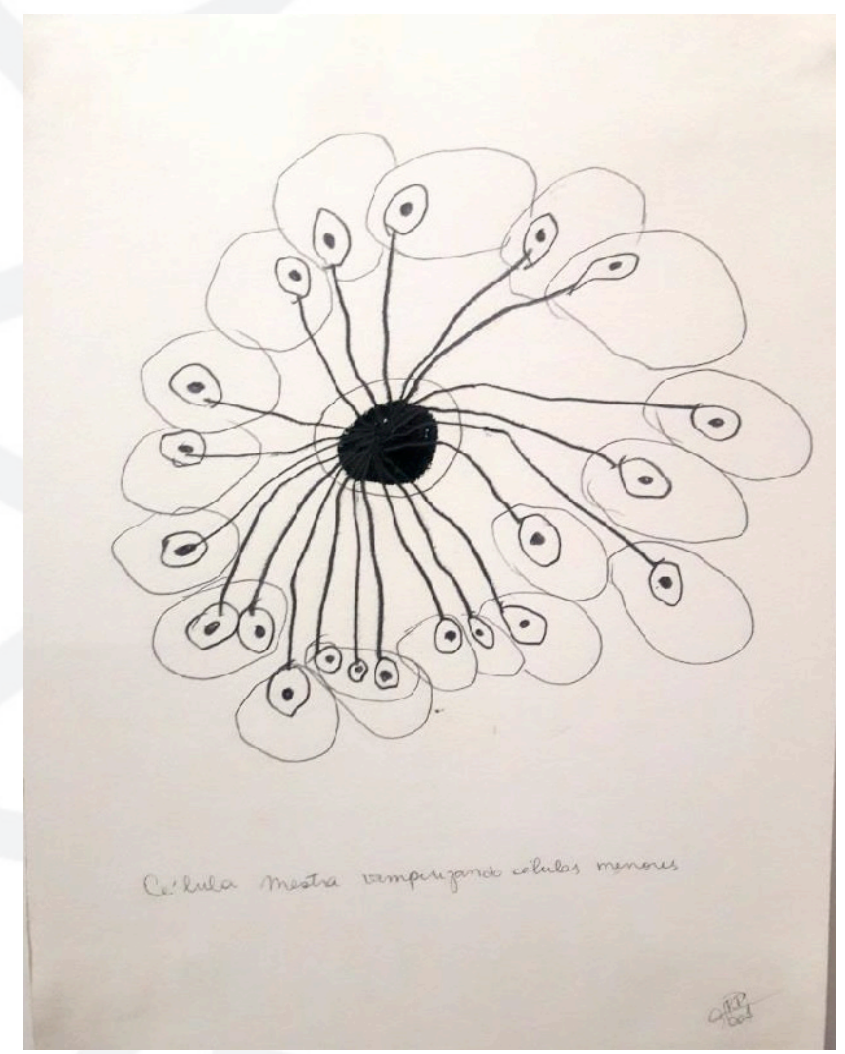

Figura 10. Rosana Paulino, Célula mestra vampirizando células menores, 2001. Coleção da artista.

Na contemporaneidade, voltamos à temática do mundo da vida. A liberdade sexual adquirida nos anos de 1960 e todas as lutas feministas de lá até hoje, deram margem para que a mulher ganhasse a posição de protagonista de sua 
história. Paulino leva essa discussão sobre o corpo feminino ao seu último (ou primeiro) reduto: o ambiente celular.

Rosana Paulino, com Célula mestre vampirizando células menores, se apropria de linhas modernas que são revistas pelo seu olhar atual: linhas que se movimentam como em Flavio, originam linhas orgânicas suaves que circunscrevem formas arredondadas com pontos escurecidos no centro. Variações tonais da linha de Anita. Linhas firmes, intensas como as de Tarsila, dadas pela espessura do gesto, dirigem-se ao núcleo do desenho que, num movimentos espiralado, irrompe numa abstração congregando todos os elementos que dão passagem ao desenho contemporâneo de Gustavo von Ha, com Projeto Tarsila, 2011, (Figura 11), - uma releitura do autorretrato, 1924, de Tarsila do Amaral, que por sua vez é claramente uma imagem construída, pois é assim que a artista quer se apresentar ao público e ao círculo modernista. Reconhecida por sua aparência arrebatora e por sua elegância ímpar, Tarsila do Amaral preocupou-se com a confecção de seus autorretratos, especialmente o de 1924, no qual surge com os cabelos presos e brincos majestosos e o Autorretrato (Monteau-Rouge), 1923, no qual surge com pele alva e casaco vermelho. Gustavo von Ha apropria-se dessa imagem histórica, redesenha-a com grafite e nanquim, materiais clássicos usados pela própria Tarsila em As costureiras. O trabalho de Von Ha fica entre a homenagem e a citação. Von Ha cria um duplo; uma ficção. Propositalmente invertida, o artista não teme em construir um simulacro, ao contrário, toma partido da imagem hegemônica e não teme em falseá-la. O artista emprega moldura entalhada e o suporte de papel é envelhecido quimicamente para escamotear o tempo nada mais contemporâneo do que "borrar" a temporalidade. O desenho de von Ha procura a expressão, como todos os anteriores. Os traços do moderno são aqui misturados ao conceitualismo, um modernismo tardio que dará passagem para toda a arte contemporânea. $O$ desenho se situa: linhas que variam e criam formas, gestos construídos com precisão, o uso de materiais como o nanquim e o carvão, e a proposição de outra presença, ou seja, aspectos que possam mapear os indícios que a arte atual vem tomando. 


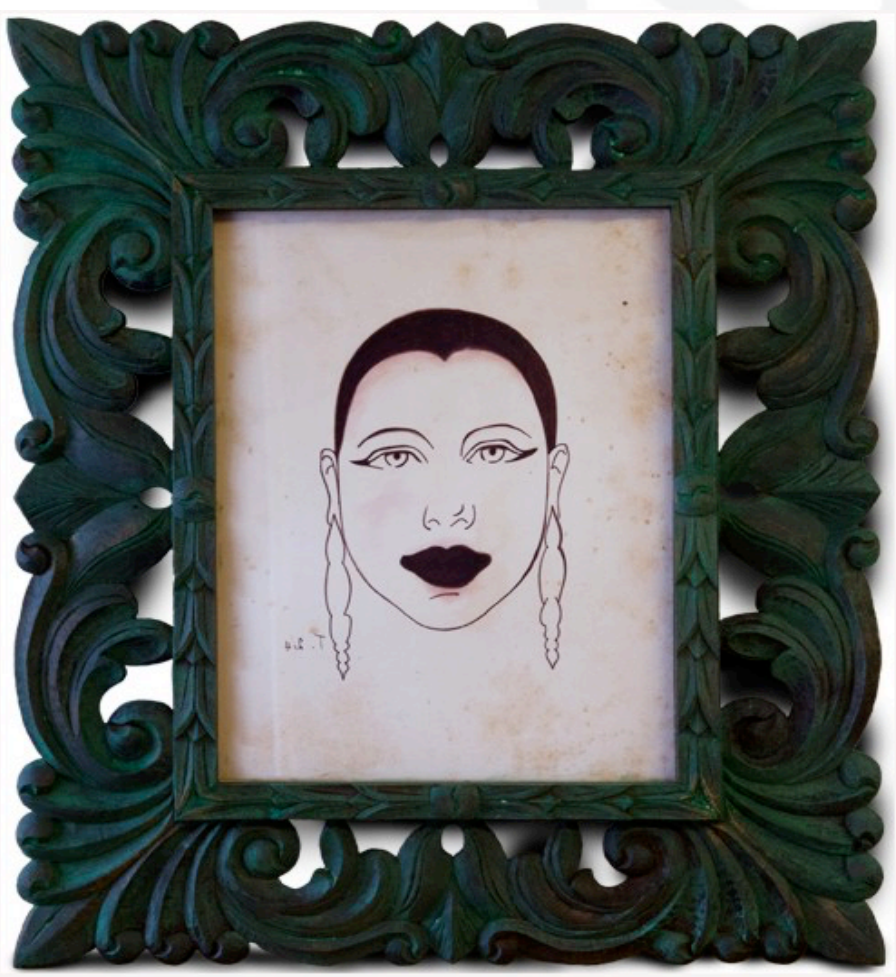

Figura 11. Gustavo von Ha, Projeto Tarsila, 2011. Acervo MAC USP.

\section{CONSIDERAÇÕES FINAIS}

Aqui, resumimos nossa proposição da crença que o exercício da percepção nos dá acesso a um olhar criador, primeiramente, como uma visão de mundo que se completa no exercício de apreensão da imagem significativa, inscrita numa matéria.

As seis obras selecionadas em Memorial do desenho nos mostram o mundo vivenciado e visto por seus produtores - visão aqui enfatizada pela temática da figura feminina: corpo, trabalho, representação, nascimento e morte nos oferecem, também, certas passagens do desenho como memória estética moderna dando indícios ao contemporâneo.

A aproximação dessas "imagens-enigma" são momentos nos quais a condição de construção de linguagem criadora está apresentando suas cifras de visualidade. Criando ou vendo a arte, podemos participar do exercício de 
perceber a qualidade do mundo. É silêncio do corpo no trabalho e aponta para o impensado que se dá a pensar.

\section{AGRADECIMENTOS}

Agradeço Alecsandra Matias de Oliveira pela cuidadosa revisão e valiosas sugestões na finalização do presente artigo.

\section{BIBLIOGRAFIA CITADA}

ADRIANI, Gotz. Joseph Beuys: Drawings, objects and prints. Stuttgart: Institute for Foreign Cultural Relations. Catalog.

ARANHA, C.S.G. e NICOLAU, E.C. Cenas de uma curadoria Samson Flexor - $A$ dobra do desenho. Revista Acadêmica (São Sebastião), São Sebastião, 2009, p. 32-44.

BAUDRILLARD, J. Simulacros e simulação. Lisboa: Relógio d'água, 1991.

CÂMARA, José Bettencourt da. Expressão e contemporaneidade. A arte moderna segundo Merleau-Ponty. Lisboa: Imprensa Nacional - Casa da Moeda. 2005.

CARMAN, Taylor e HANSEN, B.N. (Editors) The Cambridge companion to Merleau-Ponty. Cambridge: Cambridge University Press, 2005.

DIDI-HUBERMAN, Georges. Diante da Imagem: questão colocada aos fins de uma história da arte. Trad. Paulo Neves. São Paulo: Editora 34 Ltda, 2013.

FABBRINI, Ricardo Nascimento Arte e vida: do moderno ao contemporâneo. Tese de Livre-docência. FFLCH. Área de Estética. Junho/2019.

FONSECA, Andrea Matos da. Corporeidade na arte atual brasileira: sensibilidades desveladas. Dissertação de mestrado. Programa de PósGraduação interunidades em Estética e História da Arte. São Paulo, PGEHA USP. 2012.

JAMESON, Fredric. A virada cultural: reflexões sobre o pós-modernismo. Trad. Carolina Araújo. Rio de Janeiro: Civilização Brasileira, 2006.

KLEE, Paul. Sobre a arte moderna e outros ensaios. Rio de Janeiro: Jorge Zahar Ed. 2001. 
MERLEAU-PONTY, Maurice. Fenomenologia da Percepção. Trad. Carlos Alberto Ribeiro de Moura. $2^{a}$. Edição. São Paulo: Martins Fontes, 1999.

MERLEAU-PONTY, Maurice. O Oho e o Espírito. Seguido de $A$ linguagem indireta e as vozes do silêncio e $A$ dúvida de Cézanne. Trad. Paulo Neves e Maria Ermantina Galvão Gomes Pereira. São Paulo: Cosac\&Naif, 2004.

MERLEAU-PONTY, Maurice. Os Pensadores - textos selecionados / Maurice Merleau-Ponty; Traduções e notas de M. S. Chaui; São Paulo, Abril Cultural, 1980.

NICOLAU, Evandro Carlos. Por dentro do Desenho. O Imparcial. Coluna Arte para todos. Caderno Cartaz. Araraquara. 2005.

RATTO, Gianni. Antitratado de Cenografia. Variações sobre o mesmo tema. São Paulo: Ed. SENAC. 2001. N. A. Aguilar; P. S. Moraes.

\section{LISTAS DE FIGURAS}

Figura 1 a 6: Memorial do desenho, 2019. - pág.: 46

Figura 7: Anita Malfatti, Nu deitado, c. 1925. Acervo MAC USP. - pág.: 49

Figura 8: Flávio de Carvalho, Minha mãe morrendo, 1947, Acervo MAC USP. pág.: 50

Figura 9: Tarsila do Amaral, Costureiras, sd. Acervo MAC USP. - pág.: 51

Figura 10: Rosana Paulino, Célula mestra vampirizando células menores, 2001. Coleção da artista. - pág.: 52

Figura 11: Gustavo von Ha, Projeto Tarsila, 2011. Acervo MAC USP - pág. 54 